\title{
Burden of Epilepsy: The Ontario Health Survey
}

\author{
Samuel Wiebe, David R. Bellhouse, Christine Fallahay, Michael Eliasziw
}

\begin{abstract}
Background: Few data exist on the frequency and burden of epilepsy in Canada and on the impact of self-reported epilepsy in the general population. We assess the frequency, general health, psychosocial function, and health care resource use among self-identified epileptic persons in the general population. Method: The 1990 Ontario Health Survey is an omnibus, extensive health survey of 61,239 subjects representing the Ontario population. Self-reported epileptic subjects are compared with three groups, ie., those with $\geq 1$ other chronic illnesses, the general population, and those with no health problems. Results: The point prevalence of self-reported epilepsy was 5.8 per 1,000 population, a figure similar to that of active epilepsy in other studies. Quality of life, family function and social support were worse in epileptic than in other chronically ill subjects. Similarly, the epilepsy population had more disability days and limitations in activities, and lower annual income than all other groups, including the chronically ill. Accidents were no more common among epileptic subjects than among controls. Epileptic persons were high users of health care resources, including hospitalization, emergency room, psychological/social work, nursing services and telephone contact with health professionals. Barriers to health care were experienced infrequently. Small area variations in health status and care are explored. Conclusions: The health profile of self-reported epileptic subjects is similar to that obtained in studies involving defined epilepsy patients. In the general population, self-identification as having epilepsy carries a significant burden of illness, reflected in poorer health, psychosocial function, and quality of life, and higher health care resource use.
\end{abstract}

RÉSUMÉ: Le fardeau de l'épilepsie évalué d'après l'enquête ontarienne sur la santé. Introduction: Il existe peu de données sur la prévalence et le fardeau de l'épilepsie au Canada et sur l'impact de l'épilepsie rapportée par le patient dans la population en général. Nous avons évalué la prévalence, la santé en général, la fonction psychosociale et l'utilisation des services de santé chez des personnes qui se sont déclarées épileptiques dans la population en général. Méthodes: L'enquête ontarienne sur la santé faite en 1990 est une enquête universelle, extensive sur la santé de 61,239 personnes représentatives de la population de l'Ontario. Les personnes qui se sont déclarées épileptiques ont été comparées à 3 groupes, soit celles qui ont e 1 autre maladie chronique, la population en général et celles qui n'ont pas de problème de santé. Résultats: La prévalence de l'épilepsie rapportée par l'individu était de 5.8 par 1,000 individus, un nombre équivalent à celui rapporté pour l'épilepsie active dans d'autres études. La qualité de vie, la fonction familiale et le support social étaient moins bons chez les épileptiques que chez les autres personnes ayant une maladie chronique. De plus, la population épileptique avait plus de jours d'invalidité et plus de restrictions des activités et un revenu annuel moindre que les autres groupes incluant les personnes souffrant de maladies chroniques. Les accidents n'étaient pas plus fréquents chez les épileptiques que chez les contrôles. Les épileptiques utilisaient beaucoup les services de santé, incluant l'hospitalisation, les services d'urgence, de psychologie/travail social, les soins infirmiers et les contacts téléphoniques avec les professionnels de la santé. Ils rapportaient peu de barrières à l'accès aux soins de santé. De petites variations régionales dans l'état de santé et dans les soins sont explorées. Conclusions: Le profil de santé des personnes qui se sont déclarées épileptiques est semblable à celui qui a été obtenu dans d'autres études sur des patients ayant un diagnostic d'épilepsie. Dans la population en général, le fardeau de la maladie est important chez les personnes s'identifiant comme épileptiques, ce qui reflète un moins bon état de santé, de fonction psychosociale et de qualité de vie et une plus grande utilisation des ressources en matière de soins de santé.

Can. J. Neurol. Sci. 1999; 26: 263-270

In the 1990 World Health Organization's analysis of worldwide burden of disease, epilepsy ranks among the top three causes of neurological disability in developed countries, particularly among the young. ${ }^{1}$ Epilepsy has an estimated ageadjusted annual incidence of 30 to 60/100,000 and a prevalence of $6 / 1,000 .^{2}$ In the United Kingdom, the total annual cost of
From the Departments of Clinical Neurological Sciences (SW, ME), Epidemiology and Biostatistics (SW, ME) and Statistics and Actuarial Sciences (DRB, CF), University of Western Ontario, London, Ontario, Canada. RECEIVEDFEBRUARY 8, 1999. ACCEPTED IN FINALFORMMAY 18, 1999 Reprint requests to: Samuel Wiebe, London Health Sciences Centre, University Campus, 339 Windermere Road, London, Ontario, N6A5A5 
established epilepsy was estimated at US \$2,895 million in 1994. ${ }^{3}$ In addition, multi-national analyses show that epilepsy and its treatment have a significant impact on daily quality of life, well-being, and perception of stigma. ${ }^{4}$

Few Canadian data exist on the frequency of epilepsy and no data exist on the burden and frequency of self-reported epilepsy in the Canadian general population. Self-reports may not reflect precise estimates of disease frequency due to under- and overreporting. However, they provide useful information about burden of illness as perceived by individuals and about its impact on health care resource utilization. How healthy are people who perceive themselves as having epilepsy? What is their socioeconomic status? Do they consume more or less resources than people with other chronic conditions? What is their psychosocial and family function? Answers to these questions are important because the way individuals view their health is significantly related to subsequent health outcomes. For example, people with poor self-rated health have a two- to threefold increase in the risk of early death ${ }^{5}$ and use more health services than controls. ${ }^{6,7}$

Using data obtained in the 1990 Ontario Health Survey (OHS) we assess the general health, use of health care resources, socioeconomic status, quality of life (QOL) and family and psychosocial function of people in the general population who perceive themselves as suffering from epilepsy.

\section{Methods}

\section{The 1990 Ontario Health Survey (OHS)}

This was an extensive omnibus survey on health status and use of health services of the Ontario general population, ${ }^{8}$ excluding people in institutions and in reserves, which constitutes less than $2 \%$ of the Ontario population. ${ }^{9}$ Using multistage, stratified, geographic cluster sampling, the OHS included 61,239 subjects selected from 35,479 dwellings in all 42 public health units, representing the 1990 Ontario population of 8.1 million. Response rates for interviewer- and selfadministered sections were $87.5 \%$ and $77.2 \%$, respectively. ${ }^{10}$ Weights were applied to account for probability sampling. Earlier health related surveys, eg., Canada Health Survey $1981^{11}$ and Quebec Health Survey 1987, ${ }^{12}$ influenced the OHS's content and structure.

\section{Case ascertainment}

The presence of epilepsy was probed by an interviewer asking directly "Do you have epilepsy?" Subjects choosing the response option "Yes, I do have epilepsy" are considered in this analysis. In addition to epilepsy, individuals were probed about the presence of 18 specific common chronic health problems (Appendix) and were given the opportunity to list up to eight other existing chronic illnesses. Interviewer-derived information on subjects aged $\leq 12$ years was obtained from a randomly selected adult of the same household.

The Psychological General Well Being scale (PGWB) ${ }^{13}$ evaluated QOL. The General Functioning Subscale of the McMaster Family Assessment Device (MFAD) ${ }^{14}$ and the Social Support Index (SSI) ${ }^{15}$ assessed the corresponding domains. These instruments and definitions of income levels, geographic dwelling, and chronic health problems are described in the appendix.
Table 1: Demographic Features of Self-reported Epileptics

$(\mathbf{n}=313)$

Prevalence/1,000 population

5.8

Age, years (mean $\pm \mathrm{SD}$ )

$38.67 \pm 1.9$

Female:Male (\%)

Marital Status (\%)

Now married/common law

$53.09: 46.91$

Single (never married)

46.8

Widow(er)

44.2

Separated/divorced

Household size (mean \pm SD)

Location $(\%)^{*}$

Urban $\quad 88.99$

Rural

11.01

Dwelling (\%)

Single detached home $\quad 59.7$

Double row, duplex $\quad 11.5$

Apartment $\quad 27.2$

Other 1.6

Chronic health problems

No. $($ mean \pm SD)

Epilepsy only (\%)

$2.8 \pm 0.26$

Epilepsy plus 1 other $(\%)$

Epilepsy plus 2 other (\%) 20.3

Epilepsy plus $\geq 3$ other (\%)

32.5

All percentages weighted.

*See text for description.

\section{ANALYSIS}

All estimates and analyses were weighted, adjusting for the probability of being selected. Variance estimates were inflated to account for a design effect (ie., deviation from simple random sampling). Estimates are expressed as proportions or means with corresponding standard error (SE) or 95\% confidence intervals (CI). Variables of interest in people with self-reported epilepsy (the epileptic group) were compared with three other groups:

1) those with $\geq 1$ chronic health problems other than epilepsy

(the chronically ill group),

2) the general population, and

3) those with no chronic health problems (the healthy group).

Two-tailed $\mathrm{Z}$ tests assessed statistical significance of association in selected variables. Multiple univariate analyses of the epileptic population were performed using the Rao Scott correction for analysis of complex survey design. ${ }^{16}$

Table 2: Prevalence of Self-reported Epilepsy by Age

\begin{tabular}{lrcc} 
Age (years) & $\mathrm{N}$ & $\begin{array}{c}\text { weighted } \% \\
\text { of sample }\end{array}$ & prevalence/1,000 \\
\hline $0-11$ & 38 & 10.66 & 3.1 \\
$12-15$ & 20 & 3.79 & 5.7 \\
$16-24$ & 29 & 12.97 & 4.3 \\
$25-44$ & 114 & 38.85 & 5.9 \\
$45-64$ & 61 & 17.78 & 4.9 \\
$\geq 65$ & 51 & 15.95 & 7.2 \\
\hline
\end{tabular}


Table 3: Annual income, occupation and disability

\begin{tabular}{|c|c|c|c|}
\hline & $\begin{array}{c}\text { General } \\
\text { Population }\end{array}$ & $\begin{array}{l}\text { Chronically } \\
\text { IIl }\end{array}$ & Epilepsy \\
\hline \multicolumn{4}{|c|}{ Annual household income (\%):* } \\
\hline Low & 13.7 & 14.5 & 22.2 \\
\hline Not low but $<\$ 50,000$ & 39.8 & 39.9 & 36.0 \\
\hline$\geq \$ 50,000$ & 47.5 & 45.6 & 41.8 \\
\hline \multicolumn{4}{|l|}{ Occupation $(\%): * *$} \\
\hline Office & 58.1 & 59.8 & 63.4 \\
\hline Service or Transportation & 16.1 & 15.9 & 9.5 \\
\hline Primary & 25.8 & 24.3 & 27.1 \\
\hline \multicolumn{4}{|c|}{ Disability days in past 2 weeks: $* * *$} \\
\hline Mean No. $( \pm 95 \%$ CI $)$ & $0.65 \pm 0.04$ & $0.99 \pm 0.04$ & $1.57 \pm 0.21$ \\
\hline \multicolumn{4}{|c|}{ All accidents in past 12 months: } \\
\hline Mean No. $( \pm 95 \%$ CI $)$ & $0.13 \pm 0.00$ & $0.19 \pm 0.00$ & $0.15 \pm 0.00$ \\
\hline \multicolumn{4}{|c|}{$\begin{array}{l}\text { All percentages are weighted. } \\
\text { *In Canadian dollars. See appendix for definitions. } \\
\text { ** Office = managerial, administration, professional, clerical, sales } \\
\text { Primary = farming, mining, processing, construction, materials } \\
\text { handling, other } \\
\text { ***See text for definition. }\end{array}$} \\
\hline
\end{tabular}

\section{RESUlts}

\section{The Epilepsy Population (Table 1)}

Epilepsy questions were answered by 60,823 subjects $(99.3 \%$ of the total sample) of whom 313 described themselves as having epilepsy. This yielded an adjusted point prevalence rate of selfreported epilepsy of 5.8 per 1,000 , equivalent to 47,000 prevalent cases in Ontario (1990). Prevalence was highest among those aged $\geq 65$ years, ranging from $3.1 / 1,000$ to $7.2 / 1,000$ in various age groups (Table 2). The age distribution of the epilepsy population largely reflected that of the general population, with slight under- and over-representation of the 0-11 and $\geq 65$ year age groups, respectively. Most self-described epileptic subjects $(88.9 \%)$ resided in urban dwellings (Appendix) and 60\% lived in single detached homes with two other people on average. Their mean age was 39 years and gender was equally represented. Over half of the subjects had no spouse or common law. An occupation was acknowledged by $131(42 \%)$ individuals of whom $36 \%$ were in managerial, administrative or professional activities. Epilepsy was the only recognized chronic health problem for $27 \%$ of epileptic subjects. Twenty percent each had one and two additional health problems, respectively.

Only two gender-related variables exhibited statistically significant differences. Females had a higher number of health problems $(p=.025)$ and of hospital admissions within the previous year $(\mathrm{p}=.02)$. Fewer males had low income (Appendix) and fewer females had primary occupations, eg., farming, factory, construction, etc., but these were not statistically significant.

Six geographical regions were identified, ie., north east (NE), north west (NW), central east (CE), central west (CW), east (E), and south west (SW). Some significant between-region differences in the unadjusted analysis lost significance after correcting for design effect. For example, apparently significant higher household income and visits to doctors in the CE, CWand SW (the most densely populated areas), are not significant after correcting for design effect. Three variables retain statistical significance:

1) Emergency room use is highest in NE (62\%) and NW (51\%) and lowest in E (18\%) Ontario as compared with the provincial average $(35 \%)$.

2) Dental services are used most often in $\mathrm{CE}(65 \%)$ and $\mathrm{CW}$ $(68 \%)$ than in NW (39\%) and NE (44\%) regions.

Table 4: Quality of life, family function and social support

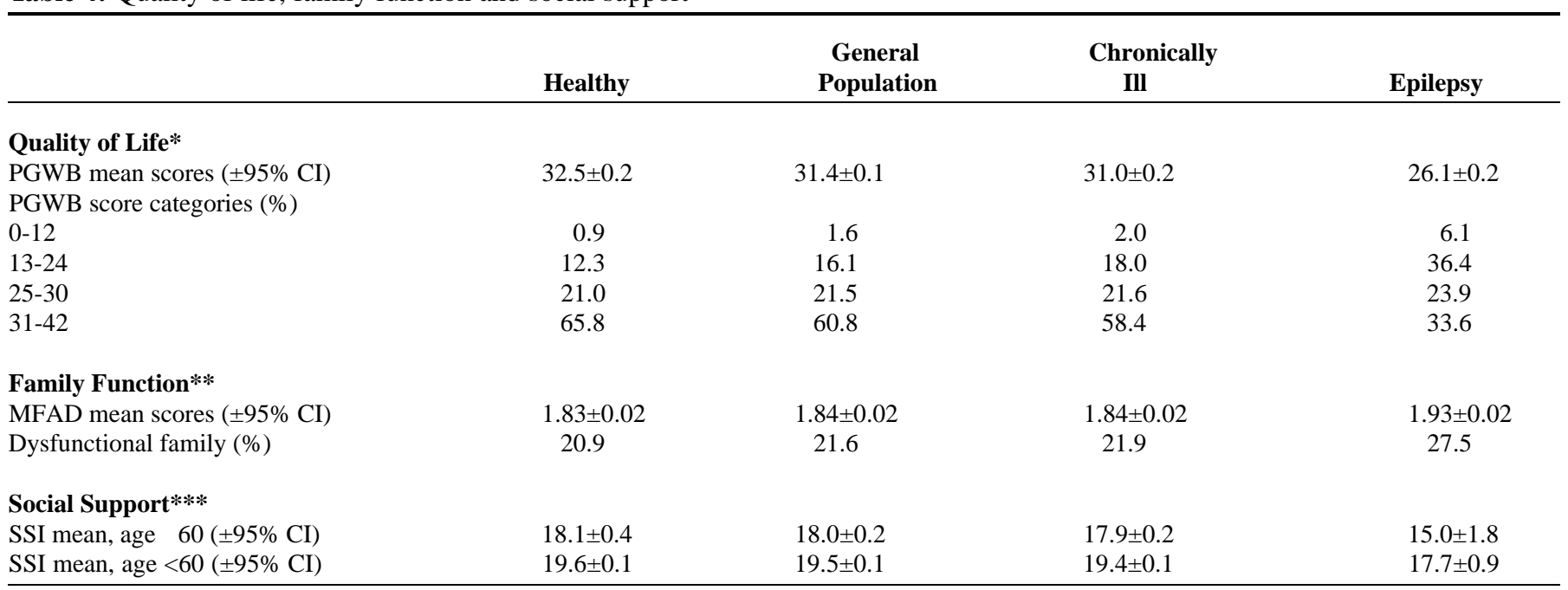

See text for abbreviations. *Higher scores $=$ better quality of life $* *$ Higher scores $=$ worse family function $* * *$ Higher scores $=$ stronger social support 
Table 5: Barriers to health care

\begin{tabular}{lcc}
\hline & \multicolumn{2}{c}{ Weighted Proportion* } \\
& Chronically Ill (\%) & Epilepsy (\%) \\
\hline Too expensive & 1.2 & 1.0 \\
Do not know MD/where to go & 0.4 & 1.4 \\
Too far/transport problems & 0.5 & 1.2 \\
Cannot get appointment & 0.7 & 1.3 \\
No hospital bed & 0.3 & 1.0 \\
Language problem & 0.1 & 0.0 \\
Too embarrassed & 0.3 & 0.2 \\
Other reason & 3.9 & 7.3 \\
\hline
\end{tabular}

*More than one item could be listed.

3) Perceived barriers to health care were highest in the CE (36\%) and NW (30\%) and lowest in the E (1\%) and SW (3\%).

Some significant differences emerged between epilepsy subjects living in urban and rural areas. The former were more frequent users of psychological/social work services (16\% vs. $4 \%)$, experienced more barriers to health care $(25 \%$ vs. $7 \%)$ and had poorer QOL (Appendix) scores (all p=.02).

Higher (better) QOLscores were obtained more frequently by epileptic persons of households with healthy family scores $(\mathrm{p}=.027)$. In addition, higher educational levels were associated with healthier families $(\mathrm{p}=.04)$.

\section{Group Comparisons}

\section{Income, occupation and disability (Table 3)}

Significantly more epileptic persons $(22.1 \%)$ had a low annual income (Appendix), than those with other chronic problems $(14.6 \%)$, the general population (13.6\%) or healthy subjects $(12 \%)$ ( $\mathrm{p}<0.001$, all comparisons). The converse was observed for high annual income.

Fewer epileptic subjects $(9.5 \%)$ were in the service or transport industry, as compared with the chronically ill or the general population ( $16 \%$ each).

The mean number of days $( \pm 95 \% \mathrm{CI})$ each person had to stay in bed or cut down on usual activities during the previous 14 days because of ill health was significantly higher for epilepsy subjects $(1.57 \pm 0.21)$ than for chronically ill $(0.99 \pm 0.04)$, the general population $(0.65 \pm 0.04)$, and healthy people $(0.02 \pm$ $0.01)$. The mean annual number of disability days $( \pm 95 \% \mathrm{CI})$ in these four groups is $41 \pm 5,26 \pm 1,17 \pm 1$, and $0.5 \pm 0.25$, respectively. Thus, in Ontario, epilepsy causes from 1.7 million to 2.2 million annual disability days (mean 1.93 million days).

The survey probed for traffic and all other accidents in the previous 12 months that resulted in an injury serious enough to limit normal activities. The mean number of accidents was slightly higher in epilepsy subjects than in the general population but lower than in other chronically ill individuals.

\section{Quality of Life, Family Function, and Social Participation (Table 4)}

On average, self-reported epileptic subjects' QOL, as measured by the PGWB scale, was significantly lower (worse) than any of the three compared groups, including the chronically ill ( $\mathrm{p}<.0001)$. More importantly, the proportion of epilepsy subjects obtaining the lowest (worst) QOLscore $(\leq 24)$ was twice that of the compared groups. Conversely, the proportion of epileptic persons with high (good) QOLscores $(\geq 31)$ was almost half that of the group with other chronic illnesses.

The OHS defined dysfunctional families as those with MFAD scores $\geq 2.17$ (Appendix). ${ }^{15}$ These were significantly more frequent among epileptic persons than among other chronically ill or the general population $(\mathrm{p}<.001)$.

Social participation indices were significantly lower for epileptic subjects than for other compared groups $(\mathrm{p}<.001)$.

\section{Access to Health Care (Table 5)}

Some barrier to health care for their chronic illness was reported by $22.75 \%$ and $7.45 \%$ of epilepsy and chronically ill respondents, respectively. Overall, specific barriers were minimal and infrequent. None exceeded $1.5 \%$ of epilepsy subjects, eg., $1.3 \%$ did not know an appropriate physician or where to go and the same proportion experienced difficulty getting an appointment.

\section{Education and Limitations (Table 6)}

On the surface, epileptic subjects' academic achievement in Ontario was similar to that of other groups, ie., $28 \%$ obtained only some or complete primary education, $41 \%$ initiated secondary instruction, and $31 \%$ engaged in post-secondary education. However, epileptic subjects were less likely than the general population to complete secondary and post-secondary education (odds ratio $=0.8$ at each level).

When asked whether ill health limited the amount or type of activities they could do as compared to healthy people of the same age and sex, one third of epilepsy subjects answered affirmatively. The corresponding proportions for the chronically ill and the general population were $11 \%$ and $7 \%$, respectively. In addition, ill health limited work or school in $72 \%$ of epilepsy respondents, as compared to $55 \%$ of those with other illnesses ( $p<.001)$. Finally, significantly fewer epileptic subjects participated in regular physical activities, as compared with the chronically ill population $(\mathrm{p}<.001)$.

Table 6: Education, health-related limitations and physical activity

\begin{tabular}{lccc}
\hline & $\begin{array}{c}\text { General } \\
\text { Population }\end{array}$ & $\begin{array}{c}\text { Chronically } \\
\text { Ill }\end{array}$ & Epilepsy \\
\hline Education: & & & \\
Primary or less & & & \\
Some secondary & 27.7 & 24.2 & 28.0 \\
Complete secondary & 21.7 & 22.6 & 23.7 \\
Some post-secondary & 19.9 & 20.7 & 17.6 \\
Complete post-secondary & 10.5 & 10.8 & 11.9 \\
& 20.2 & 21.8 & 18.8 \\
Health-Related Limitations:* & & & \\
Comparing self with healthy people & 7.1 & 10.9 & 31.8 \\
Self-perceived at work/school & - & 55.9 & 71.5 \\
& & & \\
Physical Activities (frequency): & & & \\
Regular & 48.0 & 46.6 & 32.8 \\
Occasional & 21.9 & 21.9 & 26.5 \\
Infrequent & 31.0 & 32.5 & 40.7 \\
\hline
\end{tabular}

All are weighted proportions.

*See text for definitions. 
Table 7: Utilization of Health Care Resources*

\begin{tabular}{ccccc}
\hline & & \multicolumn{2}{c}{ Proportion of Subjects (\%) } \\
& General & Chronically & \\
& Healthy & Population & Ill & Epilepsy \\
\hline
\end{tabular}

Type of service used in previous 12 months:

\section{Health Care Professionals}

$\begin{array}{lrrrr}\text { Family Doctor } & 69.4 & 81.4 & 88.1 & 92.8 \\ \text { Specialist } & 16.6 & 30.5 & 38.2 & 54.9 \\ \text { Nurse } & 5.7 & 10.0 & 12.4 & 21.0 \\ \text { Dentist } & 62.7 & 64.2 & 65.0 & 58.1 \\ \text { Pharmacist } & 7.4 & 13.7 & 17.2 & 16.9 \\ \text { Physiotherapist } & 1.4 & 5.6 & 8.0 & 6.3 \\ \text { Chiropractor } & 4.9 & 8.8 & 10.9 & 7.9 \\ \text { Psychologist/Counsellor } & 2.1 & 4.1 & 5.2 & 14.8\end{array}$

Hospital

Emergency Room

13.6

Admission

6.7

22.5

27.1

35.6

11.8

14.5

22.4

Site of most recent health service:

\begin{tabular}{|c|c|c|c|c|}
\hline Office visit & 92.5 & 86.3 & 85.7 & 75.6 \\
\hline Community clinic & 1.4 & 3.1 & 3.3 & 0.5 \\
\hline Emergency room & 1.2 & 4.8 & 5.1 & 14.9 \\
\hline Hospital clinic & 1.2 & 0.6 & 1.6 & 0.7 \\
\hline At work & 1.1 & 0.2 & 0.1 & 0.0 \\
\hline At home & 0.5 & 0.9 & 0.9 & 0.0 \\
\hline Telephone only & 1.2 & 2.0 & 2.1 & 8.1 \\
\hline
\end{tabular}

*All are weighted proportions.

\section{Use of Health Care Resources (Table 7)}

Information was obtained on utilization of health services in the previous 12 months. On average, epileptic persons visited some health professional 19.3 times, and $20 \%$ had $>25$ professional visits in one year. Epileptic persons visited their family physician or specialist an average of 9.1 times and $18 \%$ visited them $>13$ times. They also used family physician and specialist services more frequently than control groups. However, incremental use was larger for specialists than for family doctors, ie., the ratio of specialist to family doctor for epileptic subjects, chronically ill and the general population was $0.59,0.43$ and 0.38 , respectively. In addition, epilepsy respondents sought nursing services twice as frequently as the general population and other chronically ill. Thirty-five percent of epilepsy subjects had visited the emergency room (mean number of times $=2.5, \mathrm{SE} .27$ ) and $22 \%$ had been admitted to hospital (mean number of times $=1.6$, SE .84), as compared with $27 \%$ and $14 \%$ of those with chronic illnesses and $22 \%$ and $12 \%$ of the general population, respectively. Fewer epileptic subjects than other groups visited a dentist. On the other hand, optometry, pharmacy, and physiotherapy services were used with similar frequency by all groups. Epilepsy subjects utilized psychology and/or social work services three times as frequently as the chronically ill or the general population.

When asked about the type of health services received in the previous 14 days, use of emergency room and telephone advice was disproportionately high among epilepsy subjects.

\section{DISCUSSION}

Case finding methods have an impact on estimates of epilepsy frequency. While it is accepted that under-ascertainment is pervasive and that no single method will identify all cases in a population, some methods are more precise than others. In general, specialist practice-based estimates may miss up to $80 \%$ of cases unless this is the only source of readily accessible health care. ${ }^{17,18}$ Using all available medical records may miss from $7 \%$ to $27 \%$ of incident and prevalent cases found by door to door surveys. ${ }^{19}$ On the other hand, Beran et al. found their population survey to underestimate previously documented prevalent cases by $23 \%{ }^{20}$ and suggested 20/1,000 as a more accurate (corrected) prevalence ratio of epilepsy in Australia. ${ }^{21}$ This remarkably high figure stands out from international prevalence ratios. The Commission on Epidemiology and Prognosis (CEP) of the International League against Epilepsy ${ }^{22}$ does not recommend a specific ascertainment method.

Intuitively, strictness of case definition would affect prevalence estimates of active epilepsy; narrow criteria (eg., having a seizure on the day of survey) yielding lower estimates than broader criteria (eg., asking do you have epilepsy?). However, its practical effect on prevalence figures seems minimal in studies using stricter and looser criteria. ${ }^{23,24}$ Most studies qualify the definition of epilepsy in some way, eg., witnessed seizure, afebrile recurrent seizures, number/recentness 
of events, use of antiepileptic drugs, etc. The OHS used no qualifications. Thus, OHS data should be interpreted as reflecting individuals who perceive themselves as having epilepsy.

That epilepsy self-identification in the OHS reflects the health of true epileptic patients in the general population is supported by the congruence of our findings with those in the literature. For example, Austin et al. found worse QOL scores in epileptic than asthmatic children ${ }^{25}$ and Hermann et al. uncovered worse emotional well-being in epileptic than in hypertensive subjects. ${ }^{26}$ Similarly, levels of physical fitness have been worse in epileptic persons than in controls in Steinhoff et al.'s study. ${ }^{27}$ The OHS is likely to capture individuals with active epilepsy, eg., having seizures and/or taking medication. Accordingly, the observed frequency $(5.8 / 1,000)$ may be best interpreted as point prevalence of active epilepsy. This figure is similar to that of active epilepsy $(6 / 1,000)$ found in studies with various case definitions and ascertainment methods. ${ }^{2}$

The analysis provides valid health-related information about people in the general population who consider themselves as suffering from various illnesses. It also allows for comparison among different self-perceived conditions, and for approximation of the burden of illness in the general population. For example, OHS data have been used to perform comparisons between Canada and the USA with regard to use of preventive health care ${ }^{28}$ and to assess the impact of socioeconomic/health status on use of physicians' services. ${ }^{29}$ It has also provided important information on the burden of various chronic conditions, including migraine, cardiovascular and musculoskeletal diseases. ${ }^{30-33}$

Our data indicate that, in the non-institutionalized Canadian population, epilepsy is a marker of poor health, inferior quality of life, lower income, poorer family function and social support and higher health care resource utilization. In most aspects, the burden of illness is greater in self-reported epileptic persons than in those with $\geq 1$ common chronic health problems other than epilepsy. The prevalence of epilepsy is much higher in the institutionalized (30\%), ${ }^{34}$ mentally retarded (17\% to 60\%), ${ }^{35}$ and imprisoned population $(2.5 \%) .{ }^{36}$ Failure to include these segments of the population in the OHS likely underestimates the frequency and severity of epilepsy in Ontario.

The groups under comparison consistently showed a betterto-worse health status gradient, ie., healthy individuals, the general population, the chronically ill, and the epilepsy population, in that order. Indices of health care resource utilization exhibited a similar gradation. Epilepsy subjects had the highest level of hospital, emergency, medical and psychosocial services.

Observed differences among provincial regions merit comment. Perceived barriers to health care were higher in urban dwellers and in $\mathrm{CE}$ and $\mathrm{CW}$ regions (those with higher population densities). In addition to relatively easier access in less densely populated areas, this may also reflect epileptic subjects'satisfaction with access to the available level of care in rural areas. Overall, the 1990 epilepsy population was fairly satisfied with access to health care. Higher use of psychological services by urban dwellers may be due to easier access to such services in larger communities or to true differences between rural and urban epileptic subjects. For example, patients requiring higher levels of support may migrate to larger communities. The latter concept may be supported by poorer levels of well-being in urban dwellers. Finally, the reasons for higher emergency room use in the Northern regions remain unclear. More severe epilepsy is an unlikely cause, as physical health, hospital use and QOLin the region were equal to or better than those in other areas. Patient education, and administration/allocation of health services remain plausible explanations.

The educational status of Canadian people with epilepsy appears similar to that of other countries, eg., approximately $60 \%$ in Sillanpaa's Finnish study had basic education. ${ }^{37}$ However, our data indicate that epileptic persons engaging in secondary or post-secondary education are less likely than the general population to complete it successfully. Thus, their academic progress is slower or truncated.

As have others, we found family dysfunction, a known contributor to psychiatric, emotional and behavioural problems, to be worse in those with epilepsy than in controls. ${ }^{38}$ This analysis supports the notion that subjective well-being correlates importantly with physical health. ${ }^{39}$ Both were poorest in the epilepsy group than in all other groups, including the chronically ill.

It may be argued that comparing epilepsy with a broad range of chronic illnesses may be less meaningful than comparisons with neurological illnesses affecting similar age and gender groups. Comparison with published OHS data for migraine sufferers, a group demographically similar to epilepsy, is telling. Migraneurs' education was superior (primary or lower in only $12.8 \%$, post secondary in $38 \%$ ), their income was higher (only $11 \%$ had low income) and their hospitalization rate was lower (14\%). This confirms self-reported epilepsy as a marker of poorer health, lower education and income, and higher per patient health care resource use.

Estimates of productivity loss due to disability days in the epilepsy population can be approximated by considering 250 working days per year, an average Ontarian annual income of CAN \$25,902 (Revenue Canada, 1991) and an average epileptic person's two-week disability of 1.6 days. Correcting for the fraction of working days in two weeks (10/14), the number of yearly disability days is 28.6 per individual and $1,342,857$ provincially. The corresponding yearly productivity loss is $\$ 2,962.3$ per individual and $\$ 139.23$ million for the provincial epileptic population. Studies that include unemployment arrive at much higher cost estimates of productivity loss. ${ }^{3}$ Imputing average earnings to disability days as an approximation of the opportunity cost of time lost due to ill health (human capital approach) has been successfully used in previous analyses of epilepsy and other neurological illnesses.,.$^{3,31,40}$ However, some caveats apply to this method, eg., it is assumed, among other things, that all disability occurs in productive individuals. ${ }^{3,41}$ Similarly, we do not account for excess epilepsy-related mortality, estimated at $0.38 \%$ to $0.56 \%$ in some studies. ${ }^{3,42}$ Its inclusion would result in higher estimates of productivity loss. Moreover, surveys may underestimate outpatient health care utilization by as much as $20 \% .^{43}$

Because of their scope, method and purpose, omnibus population surveys often lack the disease-specific depth desired by clinicians. Thus, the OHS contains limited diagnostic and therapeutic information about any given condition, including epilepsy. Nonetheless, the current population-based analysis of the epilepsy population in 
Canada is useful in several ways. First, it demonstrates the physical and psychosocial ill health of the epilepsy population. Second, it begs important questions about these patients' health related needs and the optimum way of dealing with them. For example, efficiency may be gained by devoting more resources to structured counselling or liaison services. ${ }^{44}$ Exploring variables that determine small area variations in care may be beneficial, eg., educational efforts targeting emergency room and hospital admissions. Canadian epilepsy patients use telephone contact with health professionals extensively. Thus, readily accessible telephone services offering judicious epilepsy advice and triaging may help provide better and more efficient care. Finally, the observed pattern of ill health and resource use may assist health professionals and administrators in formulating future epilepsy-specific surveys for the Canadian population.

\section{APPENDIX}

\section{Instruments}

Family Function: General Functioning Subscale of the McMaster Family Assessment Device (MFAD), a 12-item, reliable and valid measure of family function. ${ }^{14}$ Higher scores indicate worse family function.

Quality of Life: Dupuy's Psychological General Well-Being scale $(\mathrm{PGWB})^{13}$ is a 22 -item, 6-subscale, widely used, valid and reliable instrument. Using 6-point Likert scales, individuals rate their level of energy, control of emotions, state of morale, interest in life, perceived stress and health status, and satisfaction with relationships during the previous 12 months. Higher scores indicate better quality of life.

Social Support Index: Designed specifically for the OHS, this instrument explores the number of friends/relatives the respondent felt close to, proportion of leisure time spent with others, satisfaction with social life, availability of a confidant and participation in voluntary organizations. Separate versions for individuals younger or older than 60 years were used. High indices indicate more participation in social support systems. ${ }^{15}$

\section{Definitions}

Low annual household income: Income from all sources $<\$ 12,000$ regardless of family size, $\$ 12,000$ to $\$ 19,999$ if household size $\geq 2$, or $\$ 20,000$ to $\$ 29,999$ if household size $\geq 4$.

Urban area: Census agglomeration or metropolitan areas with populations $\geq 10,000$.

Rural area: Dwellings not included in urban area.

Chronic health problems: Operationally defined as long-term, permanent or recurring physical health problems. Nineteen specific illnesses were explored by interview as follows: 1) skin allergies and other skin diseases, 2) hay fever or other allergies, $3)$ serious trouble with back pain, 4) arthritis or rheumatism, 5) other serious joint/bone problems, 6) paralysis or speech problems due to stroke, 7) asthma, 8) emphysema or chronic bronchitis or persistent cough, 9) epilepsy, 10) high blood pressure or hypertension, 11) circulatory problems, 12) heart disease, 13) diabetes, 14) urinary problems or kidney disease, 15) stomach ulcer, 16) other digestive problems, 17) goitre or thyroid trouble, 18) eye problems, for example glaucoma, cataract, 19) cancer (by type).

\section{ACKNOWLEDGEMENTS:}

Mrs. Zena Pellegatta assisted with manuscript preparation. Dr. Warren Blume provided insightful comments on an earlier draft.

\section{REFERENCES}

1. Murray CJ, Lopez AD, Jamison DT. The global burden of disease in 1990: summary results, sensitivity analysis and future directions. Bull World Health Organ 1994; 72: 495-509.

2. Hauser WA, Hesdorffer DC. Incidence and Prevalence. In: Hauser WA Hesdorffer DC. eds. Epilepsy: frequency, causes and consequences. New York: Demos, 1990: 1-51.

3. Cockerell OC, Hart YM, Sander JWAS, et al. The cost of epilepsy in the United Kingdom: An estimation based on the results of two population-based studies. Epilepsy Res 1994; 18: 249-260.

4. Baker GA, Jacoby A, Buck D, et al. Quality of life of people with epilepsy: a European study. Epilepsia 1997; 38: 353-362.

5. Mossey JM, Shapiro E. Self-rated health: a predictor of mortality among the elderly. Am J Public Health 1982; 72: 800-808.

6. Broyles RW, Manga P, Binder DA, et al. The use of physician services under a national health insurance scheme. An examination of the Canada Health Survey. Med Care 1983; 21: 1037-1054.

7. Brown EM, Goel V. Factors related to emergency department use: results from the Ontario Health Survey 1990. Ann Emerg Med 1994; 24: 1083-1091.

8. Ontario Health Survey 1990. Highlights. 1992; (Abstract)

9. Statistics Canada. Annual demographic statistics. 1997; 91-213XPB:(Abstract)

10. Ontario Health Survey 1990. User's Guide. Documentation. 1993; Vol. 1:(Abstract)

11. The Health of Canadians, Report of the Canada Health Survey. 1981; (Abstract)

12. Levasseur M. Sources and Rationalization of Questions Used in the Quebec Health Survey. Technical Manual 87-03. 1987; 8703:(Abstract)

13. Dupuy HJ. The psychological general well-being (PGWB) index. In: Wenger NK, Mattson ME, Furberg CD, et al. Assessment of Quality of Life in Clinical Trials of Cardiovascular Therapy. New York: Le Jacq, 1984: 170-183.

14. Byles J, Byrne C, Boyle MH, et al. Ontario Child Health Study: reliability and validity of the general functioning subscale of the McMaster Family Assessment Device. Fam Process 1988; 27: 97-104.

15. Ontario Health Survey 1990. User's Guide. Microdata Manual. 1993; Vol. 2:(Abstract)

16. Rao JN, Scott AJ. A simple method for the analysis of clustered binary data. Biometrics 1992; 48: 577-585.

17. De Graaf AS. Epidemiological aspects of epilepsy in Norway. Epilepsia 1974; 15: 291-299.

18. Baum HM. Transient ischemic attacks, Parkinson's disease and epilepsy: results from the 1980 National Ambulatory Medical Care Survey. Public Health 1986; 100: 368-374.

19. Haerer AF, Anderson DW, Schoenberg BS, et al. Prevalence and clinical features of epilepsy in a biracial United States population. Epilepsia 1986; 27: 66-75.

20. Beran RG, Michelazzi J, Hall L, et al. False negative response rate in epidemiologic studies to define prevalence ratios of epilepsy. Neuroepidemiology 1985; 4: 82-85.

21. Beran RG, Hall L, et al. Michelazzi J. An accurate assessment of the prevalence ratio of epilepsy adequately adjusted by influencing factors. Neuroepidemiology 1985; 4: 71-81.

22. Commission on Epidemiology and Prognosis: International League Against Epilepsy. Guidelines for Epidemiologic Studies on Epilepsy. Epilepsia 1993; 34: 592-596.

23. Gudmundsson G. Epilepsy in Iceland. A clinical and epidemiological investigation. Acta Neurol Scand 1966; 43:Suppl 25:1-124.

24. Stanhope JM, Brody JA, et al. Brink E. Convulsions among the Chamorro people of Guam, Mariana islands. I. Seizure disorders. Am J Epidemiol 1972; 95: 292-298.

25. Austin JK, Smith MS, Risinger MW, et al. Childhood epilepsy and asthma: comparison of quality of life. Epilepsia 1994; 35: 608-615. 
26. Hermann BP, Vickrey B, Hays RD, et al. A comparison of healthrelated quality of life in patients with epilepsy, diabetes and multiple sclerosis. Epilepsy Res 1996; 25: 113-118.

27. Steinhoff BJ, Neususs K, Thegeder H, et al. Leisure time activity and physical fitness in patients with epilepsy. Epilepsia 1996; 37: 1221-1227.

28. Katz SJ, Hofer TP. Socioeconomic disparities in preventive care persist despite universal coverage. Breast and cervical cancer screening in Ontario and the United States. JAMA 1994; 272: 530-534

29. Katz SJ, Hofer TP, et al. Manning WG. Physician use in Ontario and the United States: the impact of socioeconomic status and health status. Am J Public Health 1996; 86: 520-524.

30. Badley EM, Rasooly I, et al. Webster GK. Relative importance of musculoskeletal disorders as a cause of chronic health problems, disability, and health care utilization: findings from the 1990 Ontario Health Survey. J Rheumatol 1994; 21: 505-514.

31. To T, Wu K. Health care utilization and disability of migraine: the Ontario Health Survey. Can J Public Health 1995; 86: 195-199.

32. Ostbye T, Pomerleau J, Speechley M, et al. Correlates of body mass index in the 1990 Ontario Health Survey. Can Med Assoc J 1995; 152: $1811-1817$.

33. Kirk Gardner R, Steven D. An analysis of the Ontario Health Survey from a cardiovascular perspective. Can J Cardiovasc Nurs 1994; 5: 7-14.

34. Mariani E, Ferini-Strambi L, Sala M, et al. Epilepsy in institutionalized patients with encephalopathy: clinical aspects and nosological considerations. Am J Ment Retard 1993; 98 Suppl:27-33.
35. Shepherd C, Hosking G. Epilepsy in school children with intellectual impairments in Sheffield: the size and nature of the problem and the implications for service provision. J Ment Defic Res 1989; 33: 511-514.

36. Whitman S, Coleman TE, Patmon C, et al. Epilepsy in prison: elevated prevalence and no relationship to violence. Neurology 1984; 34: 775-782.

37. Sillanpaa M. Social functioning and seizure status of young adults with onset of epilepsy in childhood. An epidemiological 20-year follow-up study. Acta Neurol Scand 1983; 96: 1-81.

38. Thompson PJ, Upton D. Quality of life in family members of persons with epilepsy. In: Trimble MR Dodson WE. eds. Epilepsy and Quality of Life. New York: Raven Press Ltd. 1994: 19-31.

39. Ross CE, Hayes D. Exercise and psychologic well-being in the community. Am J Epidemiol 1988; 127: 762-771.

40. Begley CE, Annegers JF, Lairson DR, et al. Cost of epilepsy in the United States: a model based on incidence and prognosis. Epilepsia 1994; 35: 1230-1243.

41. Robinson R. Costs and cost-minimisation analysis. Br Med J 1993; 307: 726-728

42. Tennis P, Cole TB, Annegers JF, et al. Cohort study of incidence of sudden unexplained death in persons with seizure disorder treated with antiepileptic drugs in Saskatchewan, Canada. Epilepsia 1995; 36: 29-36.

43. Jobe JB, White AA, Kelley CL, et al. Recall strategies and memory for health-care visits. Milbank Q 1990; 68: 171-189.

44. Taylor MP, Readman S, Hague B, et al. A district epilepsy service, with community-based specialist liaison nurses and guidelines for shared care. Seizure 1994; 3: 121-127. 